\title{
Efeito de fontes e doses de molibdênio na sobrevivência do Bradyrhizobium e na fixação biológica de nitrogênio em soja ${ }^{(1)}$
}

\begin{abstract}
Ulisses Brigatto Albino(2) e Rubens José Campo(3)
Resumo - O molibdênio (Mo) é essencial para a soja, por participar da enzima nitrogenase, sintetizada pelas bactérias durante o processo de fixação biológica do nitrogênio $(\mathrm{FBN})$ por simbiose. A aplicação do Mo nas sementes no momento da semeadura antecede a aplicação do inoculante. O contato do Mo com o inoculante prejudica o Bradyrhizobium e, conseqüentemente, a FBN. O presente trabalho teve como objetivo estudar alternativas de fornecer Mo para a soja e a FBN sem afetar a sobrevivência da bactéria, a nodulação e a eficiência do processo de FBN. Avaliou-se, in vitro, a capacidade das estirpes de Bradyrhizobium de crescerem em meio líquido contendo concentrações crescentes de diversas fontes de Mo, e, em casa de vegetação, os efeitos de doses crescentes de molibdato de sódio e de outras fontes de Mo na sobrevivência do Bradyrhizobium, na nodulação e na eficiência da FBN. As estirpes apresentaram tolerância distinta com relação a fontes e doses de Mo; a estirpe SEMIA 5080 apresentou o melhor crescimento entre elas. A aplicação de Mo nas sementes com o inoculante deve ser evitada, porque ele reduz o número de células de Bradyrhizobium, a nodulação e a FBN. As fontes de Mo mais eficientes para a FBN são molibdato de amônio, trióxido de Mo e as fontes comerciais Grap e Comol.

Termos para indexação: Glycine max, bactéria, nodulação, oligoelementos, inoculação.
\end{abstract}

Effect of sources and levels of molybdenum on Bradyrhizobium survival and on biological nitrogen fixation in soybean

\begin{abstract}
Molybdenum (Mo) is an essential nutrient for soybean because it is a component of enzyme nitrogenase, responsible for the biological nitrogen fixation (BNF). It has been recommended for application on soybean seeds along with soybean inoculants. However, several works have showed that Mo applied together with inoculant reduce Bradyrhizobium survival, nodulation and BNF efficiency. The aim of this study was to know if there are alternative ways to supply Mo to soybean without affecting Bradyrhizobium strains survival, nodulation and BNF efficiency. The alternative ways studied in vitro were to know the growth of strains in liquid medium with different sources and levels of Mo, and in glasshouse these sources of Mo were compared with the commercial ones on their effects on bacteria survival on the seeds, nodulation and BNF efficiency. The strains of Bradyrhizobium showed different growth rate for the Mo concentration and sources tested, being the strain SEMIA 5080 the best of them. Mo application on the seeds must be avoided, because Mo reduces bacteria survival, nodulation and, BNF efficiency. The best Mo sources to BNF were ammonium molybdate, Mo trioxide and the commercial sources Grap and Comol.
\end{abstract}

Index terms: Glycine max, bacteria, root nodulation, trace elements, inoculation methods.

(1) Aceito para publicação em 7 de junho de 2000

Extraído da dissertação de mestrado apresentada pelo primeiro autor à Universidade Estadual de Londrina, PR.

${ }^{(2)}$ Rua Espírito Santo, 975 ap. 2, CEP 86010-450 Londrina, PR.

(3) Embrapa-Centro Nacional de Pesquisa de Soja, Caixa Postal 231, CEP 86001-970 Londrina, PR. E-mail: rjcampo@cnpso.embrapa.br

\section{Introdução}

O molibdênio (Mo) é um elemento encontrado em toda a crosta terrestre, principalmente em solos provenientes de rochas sedimentares (Bataglia et al., 1976). Porém, sua concentração no solo é sempre baixa, excedendo $0,04 \%$ somente em depósitos marinhos (Gupta \& Lipsett, 1981). Por causa de sua bai- 
xa concentração nos solos e utilização sem a devida reposição, o Mo tem-se esgotado, tornando-se comum a sua deficiência, principalmente, nos solos de cerrado (Sfredo et al., 1994, 1997).

Por participar da estrutura e ser ativador de diversas enzimas, o Mo é de fundamental importância a todos os vegetais. Essa importância aumenta no caso da soja, que tem a capacidade de estabelecer simbiose com microrganismos fixadores de $\mathrm{N}_{2}$ pertencentes à família Rhizobiaceae. Esses microrganismos infectam as raízes da soja e formam os nódulos, em cujo interior é sintetizado um complexo enzimático, denominado nitrogenase, que rompe a tripla ligação existente entre os átomos de $\mathrm{N}$ que formam a molécula do $\mathrm{N}_{2}$ e utilizam esses átomos para produzir duas moléculas de amônia $\left(\mathrm{NH}_{3}\right)$, que são fornecidas à planta, para sintetizar os compostos nitrogenados. A leguminosa, em contrapartida, fornece carboidratos aos microrganismos. Entre os microrganismos da família Rhizobiaceae, comumente chamados de rizóbios, as espécies Bradyrhizobium japonicum e Bradyrhizobium elkanii nodulam a soja.

A importância do Mo no processo de fixação biológica de nitrogênio (FBN) foi, primeiramente, descrita por Bortels (1930), que demonstrou que Azotobacter vinelandii, quando inoculado em meio de cultura sem $\mathrm{N}$ combinado, necessitava de Mo para crescer, o que não ocorria se a fonte de $\mathrm{N}$ do meio de cultura fosse o amônio. Posteriormente. Bulen \& LeConte (1966) demonstraram que a nitrogenase purificada continha Mo. Hoje, é sabido que o Mo faz parte do co-fator ferro molibdênio, o grupo prostético da fração dinitrogenase do complexo enzimático nitrogenase (Martens \& Westermann, 1991). A soja requer grandes quantidades de $\mathrm{N}$ dado o seu elevado teor de proteína e, na ausência da simbiose com Bradyrhizobium, chegaria a ser uma cultura inviável diante dos custos elevados que o agricultor teria com fertilizantes (Vargas \& Hungria, 1997).

Com o surgimento do problema de deficiência de Mo no solo, tornou-se necessário fornecê-lo à soja através da adubação mineral (Sfredo et al., 1997). A aplicação pode ser feita de diversas formas. No passado, o fornecimento era realizado quando a semente recebia as substâncias necessárias na forma de um pélete que a envolvia (Ruschel et al., 1970).
Atualmente, essa prática não vem sendo adotada, pois o pélete pode dificultar as trocas gasosas da semente, prejudicando-a, e diversas outras formas de aplicação de Mo têm sido descritas. Alguns autores afirmam que o melhor é aplicar o Mo no solo, antes do plantio (Johannes \& Gunarto, 1987; Vargas \& Ramirez, 1989); entretanto, em face da sua imobilização no solo, a sua eficiência seria muito inferior, requerendo, para isso, quantidades necessárias de $\mathrm{Mo}$ superiores em dez vezes, para equiparar eficiência com a de outros métodos. Hegazy et al. (1990), Yanni (1990) e Amara \& Nasr (1995) afirmam ter obtido melhores resultados quando o Mo foi aplicado via pulverização foliar. Em face da facilidade, do baixo custo e da eficiência de aplicação, a outra alternativa de aplicação do Mo é via semente, por ocasião do plantio, imediatamente antes do inoculante (Campo \& Lantmann, 1998).

Verifica-se, em estudos científicos, que as principais fontes de Mo são o molibdato de sódio, molibdato de amônio, ácido molíbdico e trióxido de Mo. Atualmente, existem, no mercado, diversos produtos comerciais fornecedores de micronutrientes, com as mais variadas formulações. Sfredo et al. (1997), trabalhando com alguns desses produtos, verificaram que a adição do Mo nas sementes aumentou a produtividade da soja em até $480 \mathrm{~kg} \mathrm{ha}^{-1}$, provando, assim, a importância desse nutriente para a cultura da soja.

A recomendação atual de aplicação do Mo em soja é via semente antes da aplicação do Bradyrhizobium. Os produtos à base de Mo podem ser líquidos ou sólidos. Os inoculantes podem ser liofilizados, líquidos ou turfosos. Para uma boa aderência e distribuição desses produtos nas sementes, a recomendação é umedecer as sementes com $300 \mathrm{~mL}$ de solução de sacarose a $10 \%$. Logo, na prática, o que tem sido feito é, se o produto contendo Mo é líquido e o inoculante é turfoso, ou vice-versa, tomar o produto líquido, completar seu volume para $300 \mathrm{~mL}$ com solução de sacarose, aplicá-lo nas sementes para umedecer, e a seguir, após homogeneização, aplicar o pó. Se ambos os produtos forem líquidos, eles são misturados e aplicados nas sementes. Assim, a bactéria estará em contato com o produto contendo Mo. Segundo Tong \& Sadowsky (1994), doses altas de Mo afetam o Bradyrhizobium, podendo diminuir o número de células viáveis na superfície da semente e 
prejudicar a nodulação e a FBN, refletindo negativamente na produtividade. Preferencialmente, pela facilidade de aplicação, o inoculante líquido vem substituindo os inoculantes turfosos. Como a turfa tem papel importante na proteção do Bradyrhizobium por ocasião da inoculação e após ela, a sobrevivência do Bradyrhizobium é ainda mais reduzida com o uso dos inoculantes líquidos. Por outro lado, não se conhece a tolerância das estirpes de Bradyrhizobium SEMIA 587, SEMIA 5019, SEMIA 5079 e SEMIA 5080, recomendadas para o uso em inoculantes comerciais na cultura da soja, em relação às fontes de Mo.

Este trabalho teve o objetivo de buscar alternativas de fornecer Mo para a soja e a FBN sem afetar a sobrevivência da bactéria, a nodulação e a eficiência do processo de FBN.

\section{Material e Métodos}

As estirpes de Bradyrhizobium, atualmente recomendadas para a produção de inoculantes comerciais para a soja, SEMIA 587, SEMIA 5019 (29W), SEMIA 5079 (CPAC 15) e SEMIA 5080 (CPAC 7) foram multiplicadas em frascos contendo $10 \mathrm{~mL}$ de meio líquido leveduramanitol (Vincent, 1970) até a fase log $\left(10^{6}\right.$ células $/ \mathrm{mL}$, calibradas pela densidade óptica). Amostras de $40 \mu \mathrm{L}$ de cada uma das estirpes foram tomadas, de forma asséptica, e usadas para inocular frascos de $30 \mathrm{~mL}$ contendo $10 \mathrm{~mL}$ de meio líquido definido (Wood \& Cooper, 1988), acrescido de concentrações crescentes de Mo $(0,0125,0,05$, $0,2,0,8,3,2$ e $12,8 \mu \mathrm{M})$, provenientes de quatro fontes (molibdato de sódio, molibdato de amônio, trióxido de molibdênio e ácido molíbdico). A dose mínima de Mo $(0,0125)$ utilizada foi a mesma usada na composição do meio de cultura, indispensável ao bom crescimento da bactéria, e por isso dispensa-se a dose zero de Mo. Os três frascos inoculados, de cada tratamento, foram incubados a $28^{\circ} \mathrm{C}$, com agitação a $110 \mathrm{rpm}$. O crescimento das diferentes estirpes, após oito dias da incubação, foi determinado pelo método de diluição decimal em placas de Petri, onde $100 \mu \mathrm{L}$ das diluições $10^{-5}, 10^{-6}$ e $10^{-7}$ foram espalhados com alça de Drigalski sobre o meio ágar leveduramanitol (Vincent, 1970). Após 10 a 12 dias de incubação a $28^{\circ} \mathrm{C}$, as colônias formadas foram contadas, e os tratamentos, comparados.

Em casa de vegetação foram realizados dois experimentos. Em um deles, estudou-se o efeito de doses de $\mathrm{Mo}$, na fonte molibdato de sódio, e no outro, fez-se a comparação das fontes comerciais de Mo com as não-comerciais, na dose de $20 \mathrm{~g}$ de $\mathrm{Mo} /$ ha, que é a dose média em uso pelos agricultores. Em ambos, após a aplicação dos tratamentos nas sementes, procedeu-se, em laboratório, à contagem do número de células viáveis de Bradyrhizobium, da seguinte maneira: duas subamostras de 100 sementes (13 g) de cada um dos tratamentos foram colocadas em erlenmeyers e lavadas por quatro vezes com agitação, em $50 \mathrm{~mL}$ de solução salina $0,85 \%$ estéril com $0,5 \%$ de Tween 80. Da solução obtida, $200 \mathrm{~mL}$, foram realizadas diluições decimais até obtenção das concentrações de $10^{-5}, 10^{-6}$ e $10^{-7}$, de onde foram retiradas amostras de $0,1 \mathrm{~mL}$ para inocular em placas de Petri contendo meio de cultura seletivo enriquecido de antibióticos e fungicidas (Ikuta, 1995), para as contagens necessárias. Paralelamente, sementes de soja dos diferentes tratamentos foram semeadas em potes de isopor com capacidade para 2 litros contendo uma mistura de pedriscos finos de rio (2 a $5 \mathrm{~mm}$ de ø) com vermiculita $(1: 1)$, esterilizados em autoclave a $1 \mathrm{~atm}$ e $120^{\circ} \mathrm{C}$, por duas horas. Cada pote recebeu uma mangueira de plástico que, por pressão de uma bomba, gotejava solução nutritiva estéril e isenta de N (Broughton \& Dilworth, 1970, citados por Somasegaran \& Hoben, 1985). Esses vasos foram mantidos em casa de vegetação de cobertura de plástico, com entrada de ar filtrado e à temperatura controlada média de $30^{\circ} \mathrm{C}$ (dia/noite). Na floração, as plantas foram coletadas para avaliação da nodulação (número e massa dos nódulos secos), da massa da parte aérea seca e do $\mathrm{N}$ total acumulado na parte aérea - este último, avaliado pelo método de Feije \& Anger (1972).

No experimento que avaliou o efeito de doses de Mo, o delineamento experimental usado foi de blocos ao acaso, com seis repetições, e com os seguintes tratamentos: duas testemunhas sem inoculação, uma sem $\mathrm{Ne}$ outra com $\mathrm{N}\left(240 \mathrm{mg} /\right.$ planta, $80 \mathrm{mg} /$ semana, na fonte $\left.\mathrm{NH}_{4} \mathrm{NO}_{3}\right)$ e cinco tratamentos submetidos a inoculação de doses de 0 , 10, 20, 40 e $80 \mathrm{~g}$ de $\mathrm{Mo} / \mathrm{ha}$, da fonte molibdato de sódio $\left(\mathrm{Na}_{2} \mathrm{MoO}_{4} \cdot 2 \mathrm{H}_{2} \mathrm{O}\right)$. As sementes de soja, cultivar BR 37, dos tratamentos-testemunha, foram desinfestadas superficialmente por imersão em álcool $70 \%$, por 30 segundos, e em solução de hipoclorito de sódio, a $10 \%$ por cinco minutos e, em seguida, lavadas cinco vezes com água destilada estéril e deixadas a secar à sombra. As doses de Mo foram dissolvidas em solução de sacarose a $10 \%$ e aplicadas nas sementes ( $6 \mathrm{~mL} / \mathrm{kg}$ semente). A seguir, procedeuse à inoculação de $1 / 10$ da dose de inoculante recomendada, ou seja, foi aplicado o inoculante turfoso, dose de $50 \mathrm{~g} / 50 \mathrm{~kg}$ de sementes contendo as estirpes SEMIA 5079 e SEMIA 5080, com concentração de $1,6 \times 10^{8}$ células por grama de inoculante. A redução da dose de inoculante, em relação à dose usada no campo, tem o objetivo de diferenciar melhor os tratamentos em casa de vegetação. Duas horas após a aplicação dos tratamentos, subamostras de 
sementes foram tomadas para determinação do número de células viáveis na semente, e para semeadura nos vasos em casa de vegetação, conforme descrito acima

No experimento que avaliou o efeito de fontes de Mo, o delineamento experimental usado foi de blocos ao acaso, com seis repetições, com os seguintes tratamentos: duas testemunhas sem inoculação, com e sem $\mathrm{N}$ mineral, na mesma fonte e dose do experimento anterior, uma testemunha submetida a inoculação e cujas sementes não receberam $20 \mathrm{~g}$ de $\mathrm{Mo} / \mathrm{ha}$, e os tratamentos infectados, após receberem a aplicação de $20 \mathrm{~g} \mathrm{de} \mathrm{Mo} / \mathrm{ha}$ de diferentes fontes de Mo. As fontes de Mo utilizadas foram: molibdato de sódio, 40\% de Mo; molibdato de amônio, 54\% de Mo; trióxido de molibdênio, 66,7\% de Mo; ácido molíbdico, $66,7 \%$ de Mo e os produtos comerciais fornecedores de Mo: Nódulus (Biosoja) contendo: Mo, 10\%; Co, 1\%; S, 1\%; Ca, 1\%; Fe, 0,2\%; Grap RF 48 (Agrocete) contendo: Mo, 10\%; Co, 1\%; Zn, 21\%; B, 1,5\%; Legumol (Nitral) contendo: $\mathrm{Mo}, 8 \%$; Co, 0,7\%; Zn, 5\%; B, 0,5\%; Cu, 0,5\%; Mn, 1\%; Cofermol pó (Pfizer) contendo: Mo, 10,63\%; $\mathrm{Co}, 1,22 \%$; Fe, 0,20\%; Comol (Basf) contendo: Co, 0,1\%; Mo, 6\% e Comol cerrado (Basf) contendo: Co, 1\% e Mo, $5 \%$. Todos os produtos foram dissolvidos em solução de sacarose a $10 \%$, e aplicados nas sementes $(6 \mathrm{~mL} / \mathrm{kg})$ antes do inoculante. A desinfestação dos tratamentos sem inoculação, a cultivar de soja utilizada, o inoculante utilizado, bem como a sua dose, foram os mesmos do experimento anterior. Similarmente ao experimento anterior, duas horas após aplicação dos tratamentos, subamostras de sementes foram tomadas para determinação do número de células viáveis na semente, e para semeadura nos vasos em casa de vegetação

Os resultados obtidos foram submetidos à análise de variância, e as médias, comparadas pelo teste de Tukey a $5 \%$ de probabilidade.

\section{Resultados e Discussão}

Quanto à fonte molibdato de sódio, as estirpes SEMIA 587 e SEMIA 5079 cresceram bem nas três doses iniciais, e a SEMIA 5080 até a dose quatro, tendo seus crescimentos reduzidos nas doses mais elevadas (Tabela 1). Por sua vez, a estirpe SEMIA 5019 não apresentou diferença significativa entre a maior e a menor dose, embora o menor crescimento ocorreu na dose de $0,8 \mu \mathrm{M}$ de Mo. A estirpe SEMIA 5080, independentemente da dose, foi a que apresentou melhor crescimento médio. Os resultados médios entre as doses de Mo mostram que as menores doses de Mo, 0,0125 e 0,05 mM, foram as mais favoráveis ao crescimento de todas as estirpes.
Quanto à fonte molibdato de amônio na média geral das doses, as quatro doses intermediárias apresentaram melhores resultados de crescimento, embora cada estirpe tenha tido comportamento diferenciado em relação às doses testadas. A estirpe SEMIA 587, por exemplo, mostrou melhor crescimento na dose de Mo 0,2 $\mu \mathrm{M}$; SEMIA 5019, nas quatro doses intermediárias; SEMIA 5079, na dose $0,05 \mu \mathrm{M}$, e SEMIA 5080, na dose $0,0125 \mu \mathrm{M}$. A dose $12,8 \mu \mathrm{M}$ de Mo foi excessiva, especialmente, para as estirpes SEMIA 587, SEMIA 5019 e SEMIA 5080. A estirpe SEMIA 5080 foi a que apresentou maior crescimento, independentemente de dose, seguida por SEMIA 587 e SEMIA 5019, que não diferiram estatisticamente entre si.

Na fonte trióxido de molibdênio, as estirpes apresentaram um crescimento similar entre si, com relação às doses de Mo. Elas cresceram bem até a dose de $0,8 \mu \mathrm{M}$, e praticamente não cresceram mais nas doses superiores. SEMIA 5080, como nas fontes anteriores, apresentou um crescimento bem superior à das demais estirpes até a dose $0,8 \mu \mathrm{M}$; nas doses superiores, ela foi igual às demais. A média de crescimento das estirpes, independentemente de dose, foi inferior ao crescimento das demais fontes de Mo.

Com relação à fonte ácido molíbdico, os melhores crescimentos médios foram obtidos nas doses $0,05,0,2$ e $0,8 \mu \mathrm{M}$ de Mo. A dose de $0,0125 \mu \mathrm{M}$ não foi suficiente para permitir o crescimento adequado da SEMIA 5079, e que a SEMIA 587 necessitou de $12,8 \mu \mathrm{M}$ de Mo para atingir o crescimento máximo. Efeitos tóxicos foram constatados nas duas doses mais elevadas da SEMIA 5019, e na dose de $12,8 \mu \mathrm{M}$, na SEMIA 5079 e SEMIA 5080. Conforme Tong \& Sadowski (1994), era esperado que, nas maiores doses de Mo, o Bradyrhizobium não se desenvolvesse bem. De fato, isto foi observado, com exceção da estirpe SEMIA 587.

A estirpe que apresentou maior taxa de crescimento em todas as fontes, com exceção de fonte ácido molíbdico, foi a SEMIA 5080, que é da espécie Bradyrhizobium japonicum. Esse fato é bastante importante, uma vez que, por ela ser dessa espécie, deveria ser menos tolerante que as da espécie de Bradyrhizobium elkanii, como tem sido verificado em outros testes, como, por exemplo, tolerância a antibióticos (Kuykendall et al., 1992; Boddey \& Hungria, 1997). 
Tabela 1. Crescimento de quatro estirpes de Bradyrhizobium em meio de cultura líquido com diferentes doses de molibdênio, proveniente de diversas fontes. Dados transformados, equivalendo a $\log \mathrm{x}+1$ do número de unidades formadoras de colônias ${ }^{(1)}$.

\begin{tabular}{|c|c|c|c|c|c|}
\hline $\begin{array}{l}\text { Dose de } \mathrm{Mo}^{(2)} \\
(\mu \mathrm{M})\end{array}$ & SEMIA 587 & SEMIA 5019 & SEMIA 5079 & SEMIA 5080 & Média \\
\hline & \multicolumn{5}{|c|}{ Molibdato de sódio } \\
\hline 0,0125 & $2,43 \mathrm{aAB}$ & $2,06 \mathrm{aB}$ & $2,26 \mathrm{aB}$ & $2,88 \mathrm{abA}$ & $2,41 \mathrm{a}$ \\
\hline 0,05 & $2,41 \mathrm{aB}$ & $1,56 \mathrm{abC}$ & $2,12 \mathrm{abBC}$ & $3,10 \mathrm{aA}$ & $2,30 \mathrm{ab}$ \\
\hline 0,2 & $1,91 \mathrm{abB}$ & $1,52 \mathrm{abB}$ & $1,68 \mathrm{abcB}$ & $3,03 \mathrm{abA}$ & $2,03 \mathrm{bc}$ \\
\hline 0,8 & $1,41 \mathrm{bB}$ & $1,09 \mathrm{bB}$ & $1,43 \mathrm{cB}$ & $2,94 \mathrm{abA}$ & $1,72 \mathrm{~cd}$ \\
\hline 3,2 & $1,49 \mathrm{bB}$ & $1,43 \mathrm{abB}$ & $1,47 \mathrm{bcB}$ & $2,44 \mathrm{bcA}$ & $1,71 \mathrm{~cd}$ \\
\hline 12,8 & $1,30 \mathrm{bB}$ & $1,58 \mathrm{abAB}$ & $1,31 \mathrm{cB}$ & $1,92 \mathrm{cA}$ & $1,53 \mathrm{~d}$ \\
\hline \multirow[t]{2}{*}{ Média } & $1,82 \mathrm{~B}$ & $1,54 \mathrm{C}$ & $1,71 \mathrm{BC}$ & $2,72 \mathrm{~A}$ & 1,95 \\
\hline & \multicolumn{5}{|c|}{ Molibdato de amônio } \\
\hline 0,0125 & $2,14 \mathrm{bB}$ & $1,15 \mathrm{bC}$ & $1,54 \mathrm{abC}$ & $3,27 \mathrm{aA}$ & $2,04 \mathrm{~b}$ \\
\hline 0,05 & $2,25 \mathrm{bB}$ & $2,38 \mathrm{aB}$ & $1,92 \mathrm{aB}$ & $3,04 \mathrm{abA}$ & $2,40 \mathrm{a}$ \\
\hline 0,2 & $3,09 \mathrm{aA}$ & $2,48 \mathrm{aB}$ & $1,22 \mathrm{bC}$ & $2,79 \mathrm{abAB}$ & $2,40 \mathrm{a}$ \\
\hline 0,8 & $2,30 \mathrm{bA}$ & $2,53 \mathrm{aA}$ & $1,38 \mathrm{abB}$ & $2,44 \mathrm{bA}$ & $2,16 \mathrm{ab}$ \\
\hline 3,2 & $2,11 \mathrm{bB}$ & $2,69 \mathrm{aA}$ & $1,27 \mathrm{bC}$ & $2,67 \mathrm{abAB}$ & $2,19 \mathrm{ab}$ \\
\hline 12,8 & $0,08 \mathrm{cB}$ & $0,08 \mathrm{cB}$ & $1,28 \mathrm{bA}$ & $0,12 \mathrm{cB}$ & $0,39 \mathrm{c}$ \\
\hline \multirow[t]{2}{*}{ Média } & $1,99 \mathrm{~B}$ & $1,89 \mathrm{~B}$ & $1,44 \mathrm{C}$ & $2,39 \mathrm{~A}$ & 1,93 \\
\hline & \multicolumn{5}{|c|}{ Trióxido de molibdênio } \\
\hline 0,0125 & $1,58 \mathrm{aB}$ & $1,15 \mathrm{aC}$ & $1,20 \mathrm{aC}$ & $3,06 \mathrm{aA}$ & $1,75 \mathrm{a}$ \\
\hline 0,05 & $1,63 \mathrm{aB}$ & $1,54 \mathrm{aBC}$ & $1,21 \mathrm{aC}$ & $3,27 \mathrm{aA}$ & $1,91 \mathrm{a}$ \\
\hline 0,2 & $1,50 \mathrm{aB}$ & $1,40 \mathrm{aB}$ & $1,59 \mathrm{aB}$ & $3,18 \mathrm{aA}$ & $1,92 \mathrm{a}$ \\
\hline 0,8 & $1,41 \mathrm{aB}$ & $1,39 \mathrm{aB}$ & $1,36 \mathrm{aB}$ & $3,05 \mathrm{aA}$ & $1,80 \mathrm{a}$ \\
\hline 3,2 & $0,14 \mathrm{bA}$ & $0,00 \mathrm{bA}$ & $0,10 \mathrm{bA}$ & $0,00 \mathrm{bA}$ & $0,06 \mathrm{~b}$ \\
\hline 12,8 & $0,00 \mathrm{bA}$ & $0,00 \mathrm{bA}$ & $0,00 \mathrm{bA}$ & $0,00 \mathrm{bA}$ & $0,00 \mathrm{~b}$ \\
\hline \multirow[t]{2}{*}{ Média } & $1,04 \mathrm{~B}$ & $0,91 \mathrm{~B}$ & $0,91 \mathrm{~B}$ & $2,09 \mathrm{~A}$ & 1,24 \\
\hline & \multicolumn{5}{|c|}{ Ácido molíbdico } \\
\hline 0,0125 & $1,04 \mathrm{bB}$ & $2,95 \mathrm{aA}$ & $0,69 \mathrm{bB}$ & $2,58 \mathrm{aA}$ & $1,81 \mathrm{~b}$ \\
\hline 0,05 & $1,00 \mathrm{bC}$ & $2,72 \mathrm{aA}$ & $1,74 \mathrm{aB}$ & $2,54 \mathrm{aA}$ & $2,00 \mathrm{ab}$ \\
\hline 0,2 & $1,10 \mathrm{bC}$ & $2,78 \mathrm{aA}$ & $1,94 \mathrm{aB}$ & $2,71 \mathrm{aA}$ & $2,13 \mathrm{a}$ \\
\hline 0,8 & $1,15 \mathrm{bC}$ & $2,76 \mathrm{aA}$ & $2,23 \mathrm{aB}$ & $2,57 \mathrm{aAB}$ & $2,18 \mathrm{a}$ \\
\hline 3,2 & $1,18 \mathrm{bC}$ & $1,10 \mathrm{bC}$ & $1,88 \mathrm{aB}$ & $2,97 \mathrm{aA}$ & $1,78 \mathrm{~b}$ \\
\hline 12,8 & $2,14 \mathrm{aA}$ & $1,04 \mathrm{bB}$ & $1,00 \mathrm{bB}$ & $0,79 \mathrm{bB}$ & $1,24 \mathrm{c}$ \\
\hline Média & $1,27 \mathrm{C}$ & $2,23 \mathrm{~A}$ & $1,58 \mathrm{~B}$ & $2,36 \mathrm{~A}$ & 1,86 \\
\hline
\end{tabular}

(1)Médias seguidas da mesma letra, maiúsculas nas linhas e minúsculas nas colunas, para cada fonte de Mo, não diferem entre si a $5 \%$ de probabilidade pelo teste de Tukey; os coeficientes de variação em relação às fontes de Mo, molibdato de sódio, molibdato de amônio, trióxido de molibdênio e ácido molíbdico foram, respectivamente, 26,6,16,3,53,3 e 9,2\%. (2)A dose zero de Mo não foi incluída, porque sem Mo a bactéria não cresce; a concentração $0,0125 \mu \mathrm{M}$ é a normal usada nos meios de cultura.

Pelos resultados apresentados, verifica-se que é possível efetuar ajustes, com base na compatibilidade entre uma ou outra estirpe em relação às diferentes fontes e doses de Mo, de forma a se incorporar aos caldos de culturas, que são usados na fabricação de inoculantes, concentrações de Mo superiores à concentração atual de Mo, $0,0125 \mu \mathrm{M}$. Pelas diferenças encontradas entre as fontes de Mo, na prática, nas condições de cultivo de soja, seria possível, ainda, utilizar os produtos comerciais contendo Mo que fossem provenientes de fontes de Mo menos tóxicos para as estirpes que estiverem incorporadas ao 
inoculante. Entretanto, estudos adicionais, nas condições de campo, necessitam ser efetuados para confirmar se tal compatibilização ocorre.

A adição de Mo antes da inoculação reduziu o número de células viáveis de Bradyrhizobium na semente, em relação ao tratamento somente infectado, nas quatro doses de Mo (Tabela 2), confirmando, assim, que este micronutriente aplicado na semente afeta a sobrevivência do Bradyrhizobium. As doses mais elevadas de Mo (40 e $80 \mathrm{~g} / \mathrm{ha}$ ) afetaram menos o Bradyrhizobium que as doses inferiores. É possível que a alta concentração de Mo, por criar uma pressão osmótica no sentido de dentro para fora, tenha evitado a entrada excessiva de Mo no citoplasma, permitindo melhor sobrevivência da bactéria nas sementes. O número de nódulos foi similar em todos os tratamentos, porém deve-se considerar que, como o experimento foi conduzido em casa de vegetação, em meio axênico, a redução do número de células não foi suficiente para afetar o estabelecimento da nodulação. A massa de nódulos secos foi inferior na menor dose de Mo (10 g), embora a diferença só tenha sido significativa para a dose de $40 \mathrm{~g}$ de Mo. A massa da parte aérea seca não diferiu entre os tratamentos. O N acumulado na parte aérea, na dose $10 \mathrm{~g}$, foi inferior ao obtido na dose de $80 \mathrm{~g}$, provavelmente como resultado da menor massa de nódulos obtida nesse mesmo tratamento, que apresentou ainda o menor número de células.

As fontes de Mo reduziram o número de células viáveis na semente em pelo menos $17 \%$ (Comol cer- rado) (Tabela 3). Mesmo contendo igual dose de Mo (20 g/ha), algumas fontes reduziram mais que outras o número de células. O produto Grap, por exemplo, causou uma redução de $88 \%$ em relação ao tratamento infectado, contrastando significativamente com o produto Comol cerrado e outros.

Como, de modo geral, a aplicação das fontes de Mo reduziu o número de células viáveis, era esperado que houvesse redução também na nodulação e na eficiência da FBN, em comparação com o tratamento somente infectado, cujo suprimento de Mo foi via solução. Tal fato, porém, não ocorreu, conforme se verifica nos dados referentes à nodulação e ao conteúdo de $\mathrm{N}$ na parte aérea, porque em cultivo de casa de vegetação, em condições axênicas, mesmo com um menor número de células, foi possível obter uma boa nodulação, e, por conseqüência, uma boa FBN, especialmente porque a demanda de $\mathrm{N}$ para a cultura no início da floração é bem inferior à demanda de $\mathrm{N}$ no enchimento de grãos. O número de nódulos por planta foi mais afetado nos tratamentos com as fontes molibdato de sódio e ácido molíbdico, em que se verificou um decréscimo de $40 \%$ no número de nódulos, em relação ao tratamento infectado na aplicação de Mo na semente.

A variável massa da parte aérea seca foi inferior à do tratamento-testemunha, somente onde foi utilizado o produto Cofermol. Quanto ao N acumulado na parte aérea, somente os produtos Legumol, Cofermol e Comol cerrado apresentaram médias inferiores à do tratamento-testemunha infectado.

Tabela 2. Efeito de doses de molibdênio, proveniente do molibdato de sódio, na sobrevivência de Bradyrhizobium, número e massa de nódulos secos por planta, massa seca da parte aérea e nitrogênio total em plantas de $\operatorname{soja}^{(1)}$.

\begin{tabular}{|c|c|c|c|c|c|}
\hline \multirow[t]{2}{*}{ Tratamento } & \multirow{2}{*}{$\begin{array}{c}\mathrm{N}^{\mathrm{o}} \mathrm{de} \\
\text { células/semente }^{(2)}\end{array}$} & \multicolumn{2}{|c|}{ Nódulos por planta } & \multicolumn{2}{|c|}{ Parte aérea } \\
\hline & & Número & Massa (g) & Massa (g/pl.) & $\mathrm{N}(\mathrm{mg} / \mathrm{pl})$. \\
\hline Inoculação $(\mathrm{I})^{(3)}$ & 3.066 & $106,2 \mathrm{a}$ & $0,5 \mathrm{ab}$ & $4,70 \mathrm{a}$ & $140 \mathrm{ab}$ \\
\hline $\mathrm{I}+10 \mathrm{~g}$ de Mo & 1.670 & $91,0 \mathrm{a}$ & $0,4 \mathrm{~b}$ & $3,79 a$ & $111 b$ \\
\hline $\mathrm{I}+20 \mathrm{~g}$ de Mo & 1.670 & $109,5 \mathrm{a}$ & $0,5 \mathrm{ab}$ & $4,27 \mathrm{a}$ & $132 \mathrm{ab}$ \\
\hline $\mathrm{I}+40 \mathrm{~g}$ de $\mathrm{Mo}$ & 2.670 & $114,5 \mathrm{a}$ & $0,6 \mathrm{a}$ & $4,64 \mathrm{a}$ & $138 \mathrm{ab}$ \\
\hline $\mathrm{I}+80 \mathrm{~g}$ de $\mathrm{Mo}$ & 2.000 & $102,8 \mathrm{a}$ & $0,5 \mathrm{ab}$ & $4,72 \mathrm{a}$ & $156 a$ \\
\hline Testemunha sem N & 0 & 0,0 & 0,0 & 0,53 & 5 \\
\hline Testemunha com $\mathrm{N}$ & 0 & 0,0 & 0,0 & 3,91 & 54 \\
\hline CV (\%) & & 5,73 & 21,2 & 14,08 & 14,8 \\
\hline
\end{tabular}

${ }^{(1)}$ Médias seguidas de mesma letra não diferem entre si a 5\% de probabilidade pelo teste de Tukey. ${ }^{(2)}$ Número de células viáveis de Bradyrhizobium por semente determinadas duas horas após a inoculação ou aplicação do Mo e inoculação, médias de duas subamostras sem análise estatística. (3)Umedecimento das sementes com $300 \mathrm{~mL} / 50 \mathrm{~kg}$ de sementes com solução de sacarose a 10\% e aplicação de $50 \mathrm{~g}$ de inoculante turfoso contendo as estirpes de Bradyrhizobium SEMIA 5079 e SEMIA 5080 na concentração de 1,6 x $10^{8}$ bactérias por grama. 
Tabela 3. Efeito de fontes de Mo na sobrevivência de Bradyrhizobium na semente de soja, número e massa de nódulos secos por planta, massa seca da parte aérea e nitrogênio total em plantas de soja ${ }^{(1)}$.

\begin{tabular}{|c|c|c|c|c|c|}
\hline \multirow[t]{2}{*}{ Tratamento } & \multirow{2}{*}{$\begin{array}{c}\mathrm{N}^{\mathrm{o}} \text { de células/ } \\
\text { semente }^{(2)}\end{array}$} & \multicolumn{2}{|c|}{ Nódulos por planta } & \multicolumn{2}{|c|}{ Parte aérea } \\
\hline & & Número & Massa (g) & Massa (g/pl.) & $\mathrm{N}(\mathrm{mg} / \mathrm{pl})$. \\
\hline Inoculação $(\mathrm{I})^{(3)}$ & 3.066 & $114 \mathrm{a}$ & $0,56 \mathrm{a}$ & $5,4 \mathrm{a}$ & $178 \mathrm{a}$ \\
\hline I + molibdato sódio & 1.666 & $70 \mathrm{~b}$ & $0,40 \mathrm{a}$ & $3,4 \mathrm{ab}$ & $107 \mathrm{ab}$ \\
\hline I + molibdato amônio & 1.800 & 109a & $0,58 \mathrm{a}$ & $4,7 \mathrm{ab}$ & $145 \mathrm{ab}$ \\
\hline I + trióxido de Mo & 1.934 & $82 \mathrm{ab}$ & $0,48 \mathrm{a}$ & $4,7 \mathrm{ab}$ & $140 \mathrm{ab}$ \\
\hline I + ácido molíbdico & 680 & $71 b$ & $0,45 \mathrm{a}$ & $4,2 \mathrm{ab}$ & $131 \mathrm{ab}$ \\
\hline I + Nódulos & 420 & $77 \mathrm{ab}$ & $0,53 \mathrm{a}$ & $4,2 \mathrm{ab}$ & $109 \mathrm{ab}$ \\
\hline $\mathrm{I}+\mathrm{Grap}$ & 367 & $98 \mathrm{ab}$ & $0,59 a$ & $4,9 \mathrm{ab}$ & $143 \mathrm{ab}$ \\
\hline I + Legumol & 887 & $83 a b$ & $0,49 \mathrm{a}$ & $3,5 \mathrm{ab}$ & $89 b$ \\
\hline I + Cofermol & 827 & $82 \mathrm{ab}$ & $0,45 a$ & $3,0 \mathrm{~b}$ & $87 \mathrm{~b}$ \\
\hline $\mathrm{I}+\mathrm{Comol}$ & 2.200 & $109 a$ & $0,54 \mathrm{a}$ & $4,7 \mathrm{ab}$ & $147 \mathrm{ab}$ \\
\hline $\mathrm{I}+$ Comol cerrado & 2.534 & $86 \mathrm{ab}$ & $0,42 \mathrm{a}$ & $3,4 \mathrm{ab}$ & $96 b$ \\
\hline Testemunha sem $\mathrm{N}$ & 0 & 0,0 & 0,0 & 0,5 & 4,9 \\
\hline Testemunha com $\mathrm{N}$ & 0 & 0,0 & 0,0 & 3,9 & 54,0 \\
\hline $\mathrm{CV}(\%)$ & & 6,1 & 25,5 & 27,0 & 31,7 \\
\hline
\end{tabular}

${ }^{(1)}$ Médias seguidas de mesma letra não diferem a 5\% de probabilidade pelo teste de Tukey. (2)Número de células viáveis de Bradyrhizobium por semente determinadas duas horas após a inoculação ou aplicação do Mo e inoculação, médias de duas subamostras sem análise estatística. (3)Umedecimento das sementes com $300 \mathrm{~mL} / 50 \mathrm{~kg}$ de sementes com solução de sacarose a 10\% e aplicação de $50 \mathrm{~g}$ de inoculante turfoso contendo as estirpes de Bradyrhizobium SEMIA 5079 e SEMIA 5080 na concentração de $1,6 \times 10^{8}$ bactérias por grama.

Embora não sejam diferentes estatisticamente dos demais produtos contendo Mo, esses três tratamentos reduziram em cerca de $50 \%$ o $\mathrm{N}$ acumulado na parte aérea, em relação ao tratamento-testemunha, enquanto os outros diminuíram, em média, 26\%.

No caso do Comol cerrado, o resultado sugere interferências na FBN, uma vez que essa fonte foi a que causou menor redução no número de células viáveis na semente. As quatro fontes não-comerciais de Mo, molibdato de sódio, molibdato de amônio, trióxido de molibdênio e ácido molíbdico, apresentaram, em casa de vegetação, $\mathrm{N}$ total na massa das plantas secas similar ao tratamento somente infectado, o que sugere que, para a FBN, as quatro são tão úteis quanto as outras fontes comerciais.

\section{Conclusões}

1. As estirpes de Bradyrhizobium SEMIA 587, SEMIA 5019, SEMIA 5079 e SEMIA 5080 diferem quanto à tolerância a fontes e doses de molibdênio.

2. SEMIA 5080 é a que apresenta melhor crescimento.

3. A aplicação de Mo nas sementes, em virtude de seu contato com o inoculante, reduz o número de células de Bradyrhizobium, a nodulação e a FBN.
4. As fontes de Mo mais eficientes para a FBN são molibdato de amônio, o trióxido de Mo, o Grap e o Comol.

5. É possível aumentar a concentração de Mo do caldo de cultura que é usado para inocular a turfa na fabricação dos inoculantes em até 1.024 vezes, dependendo da estirpe e da fonte de Mo utilizada, reduzindo, assim, o Mo a aplicar nas sementes.

\section{Referências}

AMARA, A. M.; NASR, S. A. Impact of foliar application with biofertilizers and micronutrients on the growth and yield of Bradyrhizobium inoculated soybean plants. Annals of Agricultural Science, Cairo, v. 40, n. 2, p. 567-578, 1995

BATAGLIA, O. C.; FURLANI, P. R.; VALADARES, J. M. A. S. O molibdênio em solos do Estado de São Paulo. In: CONGRESSO BRASILEIRO DE CIÊNCIA DO SOLO, 15., 1975, Campinas. Anais... Campinas : Sociedade Brasileira de Ciência do Solo, 1976. p. 107-111.

BODDEY, L. H.; HUNGRIA, M. Phenotypic grouping of Brazilian Bradyrhizobium strains which nodulate soybean. Biology and Fertility of Soils, Berlin, v. 25, p. 407-415, 1997. 
BORTELS, H. Molybdän als Katalysator bei der biologischen Stickstoffbindung. Archives of Microbiology, Berlin, v. 1, p. 333-342, 1930

BULEN, W. A.; LeCONTE, J. R. The nitrogenase system from Azotobacter: two enzyme requirements for $\mathrm{N}_{2}$ reduction, ATP-dependent $\mathrm{H}_{2}$ evolution, and ATPhydrolysis. National Academy of Sciences of the United States of America Proceedings, Washington, v. 56, p. 979986, 1966

CAMPO, R. J.; LANTMANN, A. F. Efeitos de micronutrientes na fixação biológica do nitrogênio e produtividade da soja. Pesquisa Agropecuária Brasileira, Brasília, v. 33, n. 8, p. 1245-1253, ago. 1998

FEIJE, F.; ANGER, V. Spot tests in inorganic analyses. Analytica Chimica Acta, Amsterdam, v. 149, p. 363-367, 1972

GUPTA, U. C.; LIPSETT, J. Molybdenum in soil, plants, and animals. Advances in Agronomy, Madison, v. 34, p. $73-115,1981$

HEGAZY, M. H.; EL HAWARY, F. I.; GHOBRIAL, W. N. Effect of micronutrients application and Bradyrhizobium japonicum inoculation on soybean. Annals of Agricultural Science, Cairo, v. 1, p. 381-398, 1990

IKUTA, N. Desenvolvimento de métodos de identificação e quantificação de estirpes de Bradyrhizobium japonicum. Porto Alegre : UFRGS, 1995. 90 p. Tese de Doutorado

JOHANNES, E.; GUNARTO, L. Nodulation and uptake of nitrogen and phosphorus by soybean inoculated with four strains of Bradyrhizobium japonicum and applied with phosphorus, molybdenum and copper. Philippine Agriculturist, Laguna, v. 70, p. 193-201, 1987

KUYKENDALL, L. D.; SAXENA, B.; DEVINE, T. E.; UDELL, S. E. Genetic diversity in Bradyrhizobium japonicum Jordan 1982 and a proposal for Bradyrhizobium elkanii sp. hov. Canadian Journal of Microbiology, Ottawa, v. 38, p. 501-505, 1992

MARTENS, D. C.; WESTERMANN, D. T. Fertilizers applications for correcting micronutrient deficiencies. In MORTVEDT, J. J.; COX, F. R.; SHUMAN, L. M.; WELCH, R. M. (Ed.). Fertilizers applications for correcting micronutrient deficiencies: micronutrients in agriculture. 2. ed. Madison : Soil Science Society of America, 1991. p. 549-592.
RUSCHEL,A. P.; ROCHA,A. C. M.; PENTEADO,A. F. Efeito do boro e do molibdênio aplicados a diferentes revestimentos de semente de feijão (Phaseolus vulgaris). Pesquisa Agropecuária Brasileira, Rio de Janeiro, v. 5, n. 3, p. 49-52, 1970

SFREDO, G. J.; BORKERT, C. M.; CASTRO, C. de. Estudo de micronutrientes na cultura da soja em um Latossolo Roxo eutrófico argiloso de Londrina, PR Londrina : Embrapa-CNPSo, 1994. 7 p. (Embrapa-CNPSo. Pesquisa em Andamento, 16)

SFREDO, G. J.; BORKERT, C. M.; NEPOMUCENO, A. L.; OLIVEIRA, M. C. N. Efícácia de produtos contendo micronutrientes, aplicados via semente, sobre produtividade e teores de proteína da soja. Revista Brasileira de Ciência do Solo, Campinas, v. 21, p. 41-45, 1997.

SOMASEGARAN, P.; HOBEN, H. J. Methods in legume-Rhizobium technology. Paia : University of Hawaii, 1985. $367 \mathrm{p}$.

TONG, Z.; SADOWSKY, M. J. A selective medium for the isolation and quantification of Bradyrhizobium japonicum and Bradyrhizobium elkanii strains from soils and inoculants. Applied and Environmental Microbiology, Washington, v. 60, p. 581-586, 1994.

VARGAS, M. A. T.; HUNGRIA, M. Fixação biológica do nitrogênio na cultura da soja. In: VARGAS, M. A. T.; HUNGRIA, M. (Ed.). Biologia dos solos dos cerrados. Planaltina : Embrapa-CPAC, 1997. p. 295-360.

VARGAS, R.; RAMIREZ, C. Respuesta de la soya y el maní a Rhizobium y a la fertilización con N, P y Mo en un típico pellustert de cañas, guanacaste. Agronomía Costarricense, San José, v. 13, p. 175-182, 1989.

VINCENT, J. M. Manual practico de rizobiología Buenos Aires : Hemisferio Sur, 1970. 200 p

WOOD, M.; COOPER, J. E. Acidity, aluminium and multiplication of Rhizobium trifolii: effects of initial inoculum density and growth phase. Soil Biology \& Biochemistry, Oxford, v. 20, p. 83-87, 1988.

YANNI, Y. G. Response of symbiotic interrelationship between soybean and the indigenous or inoculated microsymbiont, Bradyrhizobium japonicum, to soil application of manganese and molybdenum. World Journal of Microbiology and Biotechnology, London, v. 6, p. 289-294, 1990. 